\title{
The Relationship Between Specific Fatty Acids of Serum Lipids and Serum High Sensitivity C- Reactive Protein Levels in Morbidly Obese Women
}

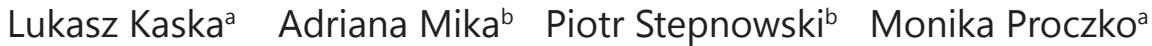 \\ Krzysztof Ratnicki-Skluckia Tomasz Sledzinskic Elzbieta Goyke ${ }^{\mathrm{d}}$ \\ Julian Swierczynskid
}

aDepartment of General, Endocrine and Transplant Surgery, Medical University of Gdansk, ${ }^{b}$ Department of Environmental Analysis, Faculty of Chemistry, University of Gdansk, 'Department of Pharmaceutical Biochemistry, Medical University of Gdansk, dDepartment of Biochemistry, Medical University of Gdansk, Gdansk, Poland

\section{Key Words}

Fatty acids $\bullet$ C-reactive protein $\bullet$ Interleukin- $6 \cdot$ Inflammation $\bullet$ Adipokines $\bullet$ Obesity

\begin{abstract}
Background/Aims: The fatty acid profile in plasma lipids contributes to the increase of plasma high sensitivity C-reactive protein (hsCRP), a marker of inflammation and predictor of cardiovascular risk. The aim of this study was to examine the relationship between specific fatty acids (FA) of serum lipids and serum hsCRP in morbidly obese woman. Methods: The study included 16 morbidly obese (mean BMI $=43 \pm 2.2 \mathrm{~kg} / \mathrm{m}^{2}$ ) non-diabetic woman awaiting bariatric surgery. FA extracted from serum lipids were methylated and analyzed on GC-MS. Commercially available ELISA kits were used to determine the serum inflammatory markers. Results: We demonstrated that total saturated FA (SFA) and total monounsaturated FA (MUFA) of serum lipids were positively correlated with serum hsCRP, whereas both $n-3$ and $n-6$ total polyunsaturated FA (PUFA) were negatively correlated with serum hsCRP. Serum interleukin- 6 correlated positively with some SFA and MUFA, whereas negatively with some of PUFA. Positive correlation between serum hsCRP and specific SFA and MUFA or negative correlation with PUFA decreased with the increased FA chain length. The number and localization of double bonds also had impact on these correlations. Conclusion: Our findings suggest that individual serum lipid FA levels, depending on the length of FA chain, number and the localization of double bonds are distinctly associated with hsCRP in morbidly obese subjects.
\end{abstract}




\section{Introduction}

Obesity is associated with elevated serum concentration of high sensitivity C-reactive protein (hsCRP), a marker of inflammation and predictor of cardiovascular risk [1]. The possible molecular mechanism linking obesity to elevated serum hsCRP concentration involves the release of several compounds by enlarged adipocytes and/or infiltrating macrophages. The list of these compounds includes many adipocytokines, among them interleukin-6 (IL-6), a key pro-inflammatory cytokine that contributes to the increase in serum hsCRP [2], and saturated fatty acids (SFA) which stimulate adipose tissue inflammation [3]. The pro-inflammatory effect of SFA is partly associated with their conversion to ceramides, which in turn activate protein kinase $\mathrm{C}$ zeta (PKC- $\zeta$ ) and mitogenactivated protein kinases (MAPK) in monocytes/macrophages [3]. The activation of these cascades stimulates the secretion of IL-6, which in turn induces synthesis of hsCRP in the liver. SFA can also stimulate the inflammatory signaling pathways via toll-like receptors and $\mathrm{NF}-\kappa \mathrm{B}$, leading to enhanced transcription of inflammatory genes [4-6]. These results suggest that an excess of SFA may amplify inflammatory response of the monocytes/macrophages accumulated in the adipose tissue of an obese subject. In contrast, monounsaturated fatty acids (MUFA) $[7,8]$ and n-3 polyunsaturated fatty acids (PUFA), especially eicosapentaenoic acid (20:5 n-3) and docosahexaenoic acid (22:6n-3) inhibit the expression of genes encoding inflammatory proteins $[6,9]$. However, the results regarding MUFA are conflicting [10]. Similarly, contradictory data suggesting either stimulatory or inhibitory effects of n-6 PUFA enriched diet on inflammation were published (see reviews $[9,11])$. According to very recently published data, specific fatty acids (FA) of various classes (i.e. SFA, MUFA or PUFA) may show distinct association with inflammatory markers $[12,13]$.

The aim of this study was to evaluate the possible associations: a) between total SFA, MUFA and PUFA contents of blood lipids and the concentrations of hsCRP, IL- 6 and other inflammatory markers (including white blood cells and neutrophils counts), as well as leptin and adiponectin (considered pro- and anti-inflammatory adipokine respectively [14]), and b) between specific FA within main classes (i.e. SFA, MUFA and PUFA) and the levels of inflammatory markers (listed above) in morbidly obese subjects.

\section{Materials and Methods}

\section{Patients}

The study included 16 morbidly obese non-diabetic woman (mean age: $43 \pm 2.8$ years, mean body mass index $-\mathrm{BMI}=43 \pm 2.2 \mathrm{~kg} / \mathrm{m}^{2}$ ) awaiting bariatric surgery at the Department of General, Endocrine and Transplant Surgery (Medical University of Gdansk, Poland). All the patients were on low calorie diet (800-1000 kcal/day, with high proteins and low fat and carbohydrates) for 3 months prior to the surgery. Dishes including lean meat, eggs, fish, cottage cheese, yoghurt, vegetables, grains, corn cereals, sponge cake, and biscuits were recommended to the patients. Blood samples for the determination of inflammatory adipocytokine levels and FA composition of serum lipids were obtained on the day of surgery, after an overnight fast. Standard laboratory parameters including hsCRP, white blood cells (WBC) and neutrophils counts were determined at the Central Clinical Laboratory of the Medical University of Gdansk. The patients' fat mass was measured with the Tanita SC 330S Body composition Analyzer. The protocol of the study conformed to the Declaration of Helsinki of the World Medical Association and was approved by the Medical University of Gdansk Ethics Committee. All the patients gave their written informed consent for participation in the study.

Enzyme-linked immunosorbent assays (ELISA) of the serum IL-6, leptin and adiponectin

Serum IL-6 levels were measured by Quantikine Human IL-6 Immunoassay (R\&D UK), containing E. coli-expressed recombinant human IL-6, and antibodies raised against the recombinant protein. Serum leptin was assayed by the DRG Leptin ELISA Kit (DRG Germany), a solid phase ELISA based on the sandwich principle. Serum adiponectin levels were measured with a Sandwich-Assay, Mediagnost ELISA for 
Adiponectin E09 (Mediagnost, Germany). The assays were performed according to the manufacturer's instructions.

Gas chromatography-mass spectrometry (GCMS) analysis of fatty acids

The total lipids were extracted according to Folch et al. [15]. 19-methyl-eicosanoate was used as the internal standard. The lipid samples were hydrolyzed and FA methyl esters (FAMEs) were prepared using 10\% Boron Trifluoride reagent $\left(\mathrm{BF}_{3} /\right.$ methanol) as we described recently [16]. After the evaporation of $n$-hexane, FAMEs were analyzed on a GC-MS QP-2010 SE (SHIMADZU). Compounds were separated on a $30 \mathrm{~m}$ x $0.25 \mathrm{~mm}$ i.d., HP-5 capillary column (film thickness $0.25 \mu \mathrm{m}$ ). The temperature

Table 1. Selected parameters of morbidly obese patients included in the study

\begin{tabular}{lcc}
\hline & Mean \pm SEM & Range \\
\hline Body mass $(\mathrm{kg})$ & $117 \pm 7.8$ & $96-187$ \\
AT mass $(\mathrm{kg})$ & $48 \pm 5.3$ & $36-82$ \\
BMI $\left(\mathrm{kg} / \mathrm{m}^{2}\right)$ & $43 \pm 2.2$ & $36-54$ \\
CRP $(\mathrm{mg} / \mathrm{L})$ & $4.6 \pm 0.78$ & $1.0-12$ \\
WBC $\left(10^{9} / \mathrm{L}\right)$ & $8.5 \pm 0.48$ & $5.8-14$ \\
Neutrophils $\left(10^{9} / \mathrm{L}\right)$ & $5.3 \pm 0.50$ & $2.8-12$ \\
IL-6 $(\mathrm{pg} / \mathrm{ml})$ & $4.9 \pm 0.63$ & $1.7-8.6$ \\
Leptin $(\mathrm{ng} / \mathrm{ml})$ & $19.3 \pm 2.3$ & $5.2-30$ \\
Adiponectin $(\mu \mathrm{gg} / \mathrm{ml})$ & $5.4 \pm 0.58$ & $2.6-9.8$ \\
Glucose $(\mathrm{mg} / \mathrm{dL})$ & $95 \pm 3.0$ & $72-189$ \\
Total cholesterol $(\mathrm{mg} / \mathrm{dL})$ & $153 \pm 8.1$ & $100-196$ \\
Triacylglycerols $(\mathrm{mg} / \mathrm{dL})$ & $113 \pm 12$ & $65-212$ \\
Insulin $(\mathrm{lU} / \mathrm{ml})$ & $7.8 \pm 1.4$ & $2.6-20$ \\
HOMA & $1.9 \pm 0.38$ & $0.7-5.7$ \\
\hline
\end{tabular}

of the column was programmed from $60^{\circ} \mathrm{C}$ to $300^{\circ} \mathrm{C}$ at a rate of $4^{\circ} \mathrm{C} \mathrm{min}^{-1}$ with helium as carrier gas at a column head pressure of $60 \mathrm{kPa}$. All the chemicals and reagents were obtained from Sigma-Aldrich.

\section{Statistical analysis}

Statistical analysis were performed with SigmaStat software. The correlations between serum FA content and selected parameters of obese patients were tested with Pearson's correlation coefficient.

\section{Results}

The characteristics of body weight, adipose tissue mass and BMI determined in morbidly obese women are presented in Table 1 . As expected, serum hsCRP was positively correlated with BMI of obese patients $(\mathrm{r}=0.56 ; \mathrm{p}<0.01)$. Moreover a positive correlation between serum IL-6 and hsCRP was found ( $\mathrm{r}=0.52 ; \mathrm{p}<0.05)$. Also a weak positive correlation between WBC (or neutrophils) count and serum CRP was observed ( $r=0.3$ ). Blood glucose, cholesterol and triacylglycerol concentrations in obese patients are presented in Table 1.

The serum levels of pro-inflammatory adipokines correlated positively with BMI of morbidly obese patients ( IL-6: $r=0.49, \mathrm{p}<0.05$; leptin: $r=0.52, \mathrm{p}<0.05$ ). In contrast, an inverse correlation was documented between BMI and the serum concentration of adiponectin, an anti-inflammatory adipokine [14] ( $r=-0.64, p<0.01)$. Essentially, also both fat mass and body weight correlated positively with serum IL- 6 and leptin and showed negative correlations with adiponectin level.

The percentages of total saturated (SFA), monounsaturated (MUFA) and polyunsaturated (PUFA) fatty acids in serum lipids of morbidly obese patients were roughly similar (Fig. 1). Oleic (18:1), palmitic (16:0) and linoleic (18:2 n-6) acids were present in greatest amounts, whereas stearic (18:0), palmitoleic (16:1) and arachidonic (20:4n-6) acids were among the less abundant (Fig. 1).

Serum concentrations of hsCRP in morbidly obese patients were inversely correlated with total PUFA, total n-3 PUFA and total n- 6 PUFA contents (Table 2). In contrast, serum hsCRP correlated positively with total MUFA and total SFA (Table 2). Since the detrimental role of high total SFA to total PUFA ratio was postulated in men [17], we also analyzed the relationship between this ratio and hsCRP in the serum of morbidly obese patients. Mean SFA/PUFA ratio in our patients was $1.32 \pm 0.12$. The SFA/PUFA ratio showed strong positive correlation with hsCRP $(\mathrm{r}=0.76 ; \mathrm{p}<0.01)$. Furthermore, we found strong positive correlations between hSCRP and SFA/n-3 PUFA $(r=0.73, \mathrm{p}<0.01)$ or SFA/n-6 PUFA ratios $(\mathrm{r}=0.75, \mathrm{p}<0.01)$.

Since the increase in the n- 6 to n-3 PUFA ratio may potentiate inflammatory processes [18], we analyzed the relationship between this parameter and hsCRP in serum of morbidly 
Fig. 1. Fatty acid composition of serum lipids in morbidly obese patients after maintaining a low calorie diet for 3 months before bariatric surgery. Data presented as mean contents of FA \pm SEM (\%). Saturated fatty acid (SFA) (white bars), monounsaturated fatty acid (MUFA) (gray bars), polyunsaturated fatty acid (PUFA) (black bars).

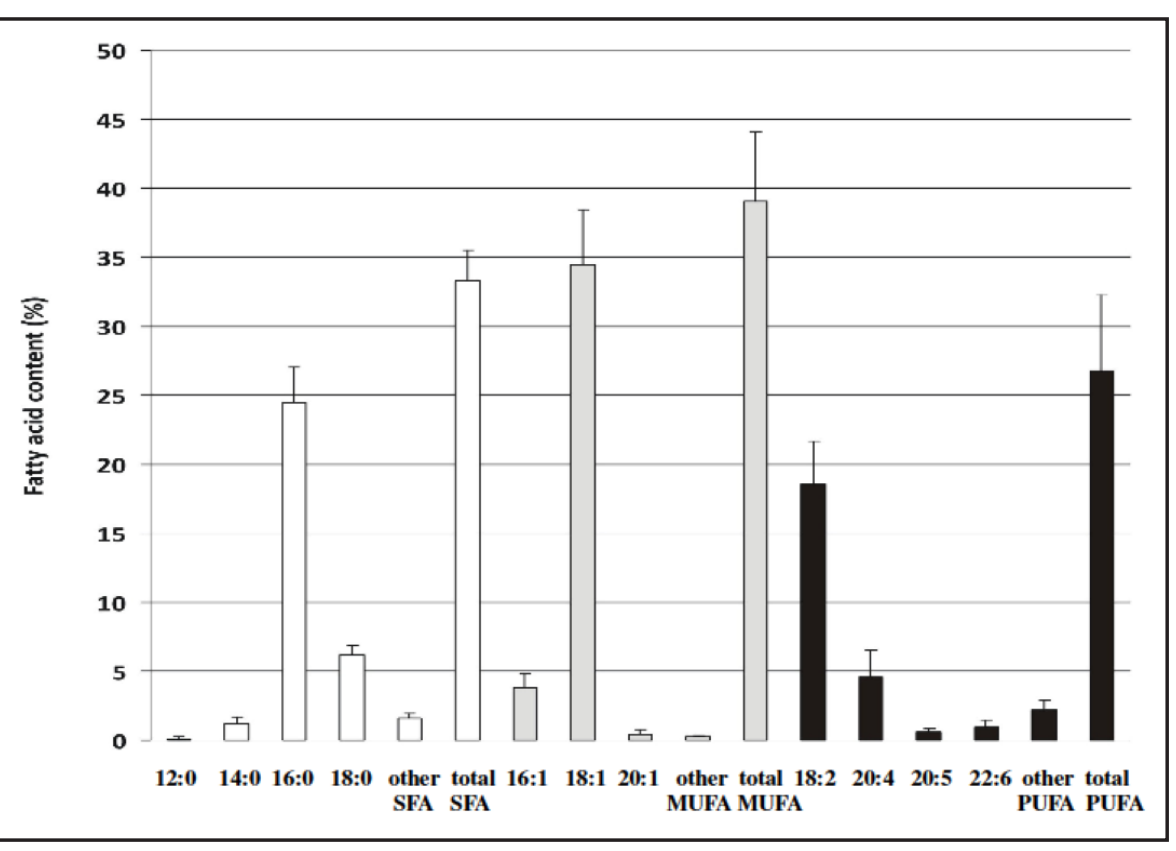

obese patients. The $n-6$ to $n-3$ PUFA ratio turned out to correlate positively with hsCRP ( $\mathrm{r}=0.77, \mathrm{p}<0.01)$.

Detailed analysis of associations between the levels of selected FA and serum hsCRP and IL-6 are presented in Table 2. Among SFA, lauric (12:0) and myristic (14:0) acids showed strong positive correlation with hsCRP, whereas a week positive correlation with this parameter was documented for palmitic acid (16:0). No significant correlations was found between stearic acid (18:0) and serum hsCRP (Table 2 ). The level of lauric acid (12:0) correlated positively with serum concentrations of IL-6 (Table 2). Similar to lauric acid (12:0), also the level of myristic acid (14:0) correlated positively with serum concentrations of IL-6 (Table 2). The levels of palmitoleic (16:1) and oleic (18:1) acid correlated positively with hsCRP concentration (Table 2). Also a week positive correlation between gadoleic acid (20:1) and hsCRP was found, but turned out to be insignificant on statistical analysis (Table 2). The content of palmitoleic acid (16:1) correlated positively with IL-6 (Table 2). In turn, gadoleic acid (20:1) showed positive correlation
Table 2. Correlations between serum FA content and selected parameters assayed in serum of morbidly obese patients. ${ }^{*} \mathrm{p}<0.01 ;{ }^{\#} \mathrm{p}<0.05$

\begin{tabular}{|c|c|c|c|}
\hline & & CRP & IL6 \\
\hline \multirow{8}{*}{$\underset{\sim}{\mathbb{S}}$} & Total SFA & $0.49^{\#}$ & -0.02 \\
\hline & lauric $(12: 0)$ & $0.75^{*}$ & $0.72^{*}$ \\
\hline & myristic $(14: 0)$ & $0.65^{*}$ & $0.67^{*}$ \\
\hline & palmitic (16:0) & 0.36 & 0.07 \\
\hline & stearic $(18: 0)$ & 0.14 & 0.37 \\
\hline & arachidic (20:0) & 0.20 & 0.14 \\
\hline & behenic $(22: 0)$ & -0.32 & $-0.58 *$ \\
\hline & lignoceric (24:0) & -0.19 & -0.37 \\
\hline \multirow{6}{*}{$\begin{array}{l}\mathbb{S} \\
\stackrel{5}{\Xi}\end{array}$} & Total MUFA & $0.60^{*}$ & 0.31 \\
\hline & myristoleic (14:1) & $0.73^{*}$ & 0.07 \\
\hline & palmitoleic (16:1) & $0.72^{*}$ & $0.61^{*}$ \\
\hline & oleic $(18: 1)$ & $0.52^{\#}$ & 0.19 \\
\hline & gadoleic $(20: 1)$ & 0.34 & $0.57 \#$ \\
\hline & nervonic $(24: 1)$ & -0.06 & 0.18 \\
\hline \multirow{10}{*}{$\begin{array}{l}\overleftrightarrow{5} \\
\stackrel{\square}{\Omega}\end{array}$} & Total PUFA & $-0.63^{*}$ & -0.31 \\
\hline & linoleic (18:2) & $-0.67^{*}$ & -0.34 \\
\hline & arachidonic (20:4) & $-0.51^{\#}$ & $-0.53^{\#}$ \\
\hline & Dihomo- $\gamma$-linolenic $(20: 3)$ & -0.41 & -0.01 \\
\hline & adrenic (22:4) & -0.31 & -0.15 \\
\hline & Total n6 PUFA & $-0.67^{*}$ & -0.29 \\
\hline & eicosapentaenoic (20:5) & $-0.69^{*}$ & -0.20 \\
\hline & docosahexaenoic (22:6) & $-0.57^{\#}$ & $-0.47 \#$ \\
\hline & docosapentaenoic $(22: 5)$ & -0.39 & -0.08 \\
\hline & Total n3 PUFA & $-0.63^{*}$ & -0.31 \\
\hline
\end{tabular}

solely with IL-6 level (Table 2). Contrary to individual SFA and MUFA, both n-6 PUFA, including linoleic acid (18:2), and n-3 PUFA, including eicosapentaenoic acid (20:5n-3) and docosahexaenoic acid (22:6n-3), showed significant inverse correlations with serum hsCRP levels (Table 2). Moreover, arachidonic acid (20:4 n-6) and docosahexaenoic acid (22:6 n-3) turned out to be inversely correlated with serum IL-6. The negative 


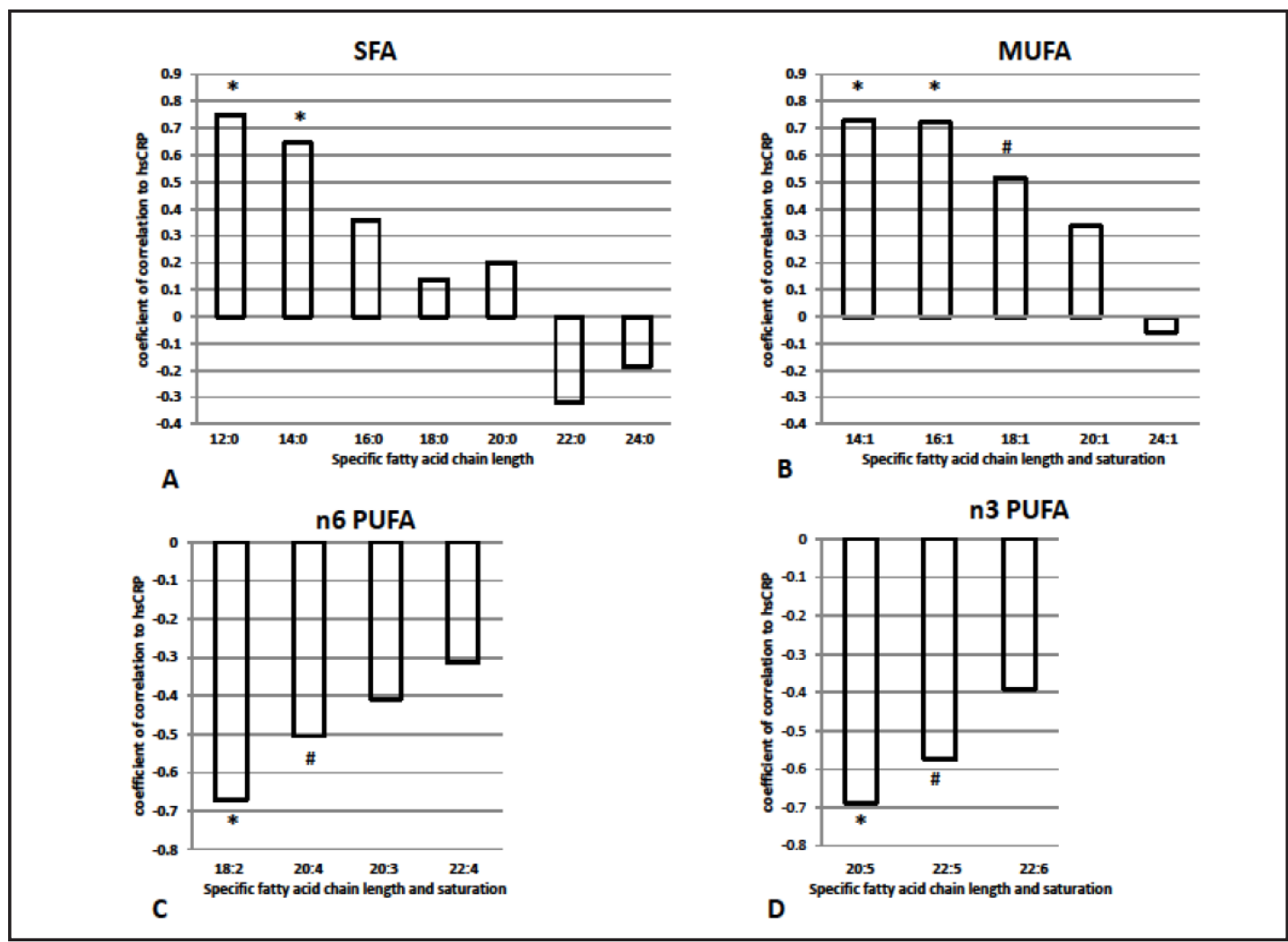

Fig. 2. Relation between the values of correlation coefficient (between serum hsCRP concentration and level of specific FA) and FA chain length, presence of double bonds, degree of unsaturation and localization of double bonds in serum lipids of morbidly obese patients. SFA (A), MUFA (B), n-3 PUFA (C) and n-6 PUFA (D).

correlations between IL-6 and other n-3 and n-6 PUFA did not prove significant on statistical analysis.

The level of lauric acid (12:0) correlated positively with WBC $(r=0.62, p<0.01)$ and neutrophil $(r=0.49, p<0.05)$ counts. The level of myristic acid (14:0) also correlated positively with WBC $(r=0.49, \mathrm{p}<0.05)$ and neutrophil $(\mathrm{r}=0.49, \mathrm{p}<0.05)$ counts. The content of palmitoleic acid (16:1) correlated positively serum leptin levels $(r=0.56, p<0.05)$, as well as with WBC and neuthrophil counts $(r=0.55, \mathrm{p}<0.05$ and $\mathrm{r}=0.48, \mathrm{p}<0.05$ respectively).

The relationship between SFA chain length and the power of correlation between individual SFA and hsCRP is presented in Figure 2. Based on this data, the association between individual SFA and hsCRP seems to be determined by FA chain length. Moreover, the results presented in Figure 2 suggest that the potential pro-inflammatory effect of MUFA and the anti-inflammatory effect of both n-3 and n-6 PUFA depend on the chain length, number and localization of double bonds.

\section{Discussion}

Our results indicate that both total SFA and MUFA are positively correlated with serum hsCRP, whereas both total n- 6 and n-3 PUFA show inverse correlation with this parameter in morbidly obese women. Moreover, our findings suggest that pro-inflammatory effect of SFA depends on their chain length. While shorter SFA lauric acid (12:0) and myristic acid (14:0) displayed strong positive correlation with serum hsCRP, a weak positive correlation was observed with palmitate (16:0) and no significant associations were documented for SFA with longer chains: stearic (18:0), arachidic (20:0), behenic (22:0), and lignoceric (24:0) 
acids. This agree with data suggesting that shorter FA (up to 16:0) but not stearic acid (18:0) were significantly associated with increased cardiovascular disease mortality [19]. Recently a positive correlation between the intake of lauric acid (12:0), myristic acid (14:0), SFA/ PUFA ratio and serum levels of hsCRP was reported in healthy men, but not in women [17]. We found strong correlation between lauric acid (12:0), myristic acid (14:0), SFA/PUFA ratio and hsCRP levels in morbidly obese female patients.

Our findings suggest that the presence of double bonds increases the pro-inflammatory properties of MUFA (compare data on Fig. 2A and 2B). Most of blood MUFA originates from desaturation of SFA catalyzed by stearyl-CoA desaturase (SCD1) in liver and adipose tissue [20]. This process is postulated to play a role in inflammation, insulin and leptin resistance [10].

The relationship between the chemical structure of PUFA and the anti-inflammatory action of these FA is more complex. The anti-inflammatory effect of PUFA (both n-3 and n- 6 ) seems to be determined by chain length, number and localization of double bonds. The antiinflammatory effects of PUFA were already documented in previous studies [21-26]. However, it should be noted that eicosanoids derived from n-6 PUFA generally have pro-inflammatory properties, while n-3 PUFA-derived eicosanoids are considered anti-inflammatory [27]. The strong positive correlation $(R=0.77)$ between $n-6 / n-3$ PUFA ratio and serum hsCRP levels documented in our patients suggest that, in fact, the proportion of $n-6$ to $n-3$ PUFA is pivotal for the severity of inflammation, expressed by serum hsCRP concentration.

The finding that pro- and anti-inflammatory effects of FA depend on the chemical structure (chain length, the number and localization of double bonds) of specific FA may be helpful for understanding the role of these compounds in other disorders such as cardiovascular diseases (atherosclerosis) and insulin resistance [28]. Moreover, one has to keep in mind that a diet rich in SFA, generally assumed pro-inflammatory, may contain specific (longer) SFA which do not modulate the severity of inflammation. Similarly, a diet enriched in PUFA, generally considered anti-inflammatory, may contain specific PUFA which exert no significant effect on inflammation (Fig.2).

The key question is why the association with serum hsCRP was observed solely for shorter SFA and MUFA. Previously published data [12, 13, 29, 30] suggest that this can be associated with different activation of toll-like receptors by shorter and longer SFA or MUFA. While palmitate (16:0) was shown to regulate the toll-like receptors, no such effect was documented in the case of stearate [13]. This is consistent with the results presented here. Moreover, the analysis of 6 different SFA (caprylic (8:0); capric (10:0); lauric 12:0); myristic (14:0); palmitic (16:0) and stearic (18:0) acids showed that lauric acid (12:0) is a much more potent activator of toll-like receptor than palmitic acid (16:0), and the latter has stronger activating potential than stearic acid (18:0) [13]. Also this pattern resembles the results presented in Fig. 2.

This study has some limitations. Firstly, it's the cross-sectional nature did not allow for identification any causative relationship. These could be elucidated, at least partially, by studying the effect of specific SFA, MUFA and PUFA (and their combination) on adipocytokines (IL-6, leptin and adiponectin) synthesis in adipocytes isolated from human adipose tissue. Secondly, the number of investigated patients was relatively small which diminished the statistical power of the sample. Thirdly, the food intake was not assessed accurately, as our participants were provided dietary advice regarding low-fat and low-carbohydrate foods and their caloric values, but not the ready-to-eat meals, so patients consumed 800-1000 kcal/ day, but individual food composition was varied. Thus, our findings should be interpreted with care.

In conclusion, we revealed that serum hsCRP of morbidly obese women is positively correlated with total SFA and total MUFA contents and inversely associated with total PUFA level. The pro-inflammatory effect of specific SFA depends on their chain length. Shorter SFA display positive correlation with serum hsCRP, and those longer than palmitate (16:0) do not. The potential pro-inflammatory effect of MUFA depends on their chain length, and on the presence of double bonds. The relationship between chemical structure of PUFA and 
their anti-inflammatory action is determined by their chain length, degree of unsaturation and localization of double bonds. The total SFA/total PUFA ratio and n-6/n-3 PUFA ratio also strongly correlate with serum hsCRP. Our findings suggests that diet rich in n-3 PUFA and low in SFA, especially lauric (12:0) and myristic (14:0) acids and MUFA, especially palmitoleic (16:1) and oleic (18:1) acids could be considered to attenuate inflammation in morbidly obese patients, however this requires further studies.

\section{Acknowledgements}

This study was supported by Medical University of Gdansk (grants no. ST-40, ST-41 and ST-89) and the Ministry of Science and Higher Education of the Republic of Poland, from the quality - promoting subsidy, under the Leading National Research Centre (KNOW) programme for the years 2012 - 2017 and grant no. DS 530-8110-D195-13-1E.

\section{Disclosure Statement}

We have no conflict of interest to disclose.

\section{References}

1 Choi J, Joseph L, Pilote L: Obesity and C-reactive protein in various populations: a systematic review and meta-analysis. Obes Rev 2013;14:232-244.

-2 Van Gaal LF, Mertens IL, De Block CE: Mechanisms linking obesity with cardiovascular disease. Nature 2006;444:875-880.

-3 Schwartz EA, Zhang WY, Karnik SK, Borwege S, Anand VR, Laine PS, Su Y, Reaven PD: Nutrient modification of the innate immune response: a novel mechanism by which saturated fatty acids greatly amplify monocyte inflammation. Arterioscler Thromb Vasc Biol 2010;30:802-808.

4 Chait A, Kim F: Saturated fatty acids and inflammation: who pays the toll? Arterioscler Thromb Vasc Biol 2010;30:692-693.

5 Yeop HC, Kargi AY, Omer M, Chan CK, Wabitsch M, O'Brien KD, Wight TN, Chait A: Differential effect of saturated and unsaturated free fatty acids on the generation of monocyte adhesion and chemotactic factors by adipocytes: dissociation of adipocyte hypertrophy from inflammation. Diabetes 2010;59:386-396.

6 Lee JY, Zhao L, Hwang DH: Modulation of pattern recognition receptor-mediated inflammation and risk of chronic diseases by dietary fatty acids. Nutr Rev 2010;68:38-61.

7 van Dijk SJ, Feskens EJ, Bos MB, Hoelen DW, Heijligenberg R, Bromhaar MG, de Groot LC, de Vries JH, Muller M, Afman LA: A saturated fatty acid-rich diet induces an obesity-linked proinflammatory gene expression profile in adipose tissue of subjects at risk of metabolic syndrome. Am J Clin Nutr 2009;90:1656-1664. van Dijk SJ, Feskens EJ, Bos MB, de Groot LC, de Vries JH, Muller M, Afman LA: Consumption of a high monounsaturated fat diet reduces oxidative phosphorylation gene expression in peripheral blood mononuclear cells of abdominally overweight men and women. J Nutr 2012;142:1219-1225.

-9 Calder PC: Long chain fatty acids and gene expression in inflammation and immunity. Curr Opin Clin Nutr Metab Care 2013;16:425-433.

10 Sampath H, Ntambi JM: The role of stearoyl-CoA desaturase in obesity, insulin resistance, and inflammation. Ann N Y Acad Sci 2011;1243:47-53.

11 Johnson GH, Fritsche K: Effect of dietary linoleic acid on markers of inflammation in healthy persons: a systematic review of randomized controlled trials. J Acad Nutr Diet 2012;112:1029-1041.

-12 Perreault M, Roke K, Badawi A, Nielsen DE, Abdelmagid SA, El Sohemy A, Ma DW, Mutch DM: Plasma levels of 14:0, 16:0, 16:1n-7, and 20:3n-6 are positively associated, but 18:0 and 18:2n-6 are inversely associated with markers of inflammation in young healthy adults. Lipids 2014;49:255-263. 


\begin{tabular}{|c|c|}
\hline Cell & Cell Physiol Biochem 2014;34:1101-1108 \\
\hline and Biochemistry & $\begin{array}{l}\text { DoI: 10.1159/000366324 } \\
\text { Publisned oninne: September } 16,2014\end{array}$ \\
\hline
\end{tabular}

13 Shaw B, Lambert S, Wong MH, Ralston JC, Stryjecki C, Mutch DM: Individual saturated and monounsaturated fatty acids trigger distinct transcriptional networks in differentiated 3T3-L1 preadipocytes. J Nutrigenet Nutrigenomics 2013;6:1-15.

14 de Heredia FP, Gomez-Martinez S, Marcos A: Obesity, inflammation and the immune system. Proc Nutr Soc 2012;71:332-338.

15 Folch J, Lees M, Sloane Stanley GH: A simple method for the isolation and purification of total lipides from animal tissues. J Biol Chem 1957;226:497-509.

-16 Sledzinski T, Mika A, Stepnowski P, Proczko-Markuszewska M, Kaska L, Stefaniak T, Swierczynski J: Identification of cyclopropaneoctanoic acid 2-hexyl in human adipose tissue and serum. Lipids 2013;48:839-848.

17 Santos S, Oliveira A, Casal S, Lopes C: Saturated fatty acids intake in relation to C-reactive protein, adiponectin, and leptin: a population-based study. Nutrition 2013;29:892-897.

18 Molendi-Coste 0, Legry V, Leclercq IA: Why and how meet n-3 PUFA dietary recommendations? Gastroenterol Res Pract 2011;2011:364040.

19 Warensjo E, Sundstrom J, Vessby B, Cederholm T, Riserus U: Markers of dietary fat quality and fatty acid desaturation as predictors of total and cardiovascular mortality: a population-based prospective study. Am J Clin Nutr 2008;88:203-209.

20 Petersson H, Lind L, Hulthe J, Elmgren A, Cederholm T, Riserus U: Relationships between serum fatty acid composition and multiple markers of inflammation and endothelial function in an elderly population. Atherosclerosis 2009;203:298-303.

21 Chrysohoou C, Panagiotakos DB, Pitsavos C, Das UN, Stefanadis C: Adherence to the mediterranean diet attenuates inflammation and coagulation process in healthy adults: The ATTICA Study. J Am Coll Cardiol 2004;44:152-158.

-22 Esposito K, Marfella R, Ciotola M, Di Palo C, Giugliano F, Giugliano G, D'Armiento M, D'Andrea F, Giugliano D: Effect of a mediterranean-style diet on endothelial dysfunction and markers of vascular inflammation in the metabolic syndrome: a randomized trial. JAMA 2004;292:1440-1446.

23 Pischon T, Hankinson SE, Hotamisligil GS, Rifai N, Willett WC, Rimm EB: Habitual dietary intake of n-3 and n-6 fatty acids in relation to inflammatory markers among US men and women. Circulation 2003;108:155160 .

24 Balk EM, Lichtenstein AH, Chung M, Kupelnick B, Chew P, Lau J: Effects of omega-3 fatty acids on serum markers of cardiovascular disease risk: a systematic review. Atherosclerosis 2006;189:19-30.

25 Micallef MA, Garg ML: Anti-inflammatory and cardioprotective effects of n-3 polyunsaturated fatty acids and plant sterols in hyperlipidemic individuals. Atherosclerosis 2009;204:476-482.

26 Zampelas A, Panagiotakos DB, Pitsavos C, Das UN, Chrysohoou C, Skoumas Y, Stefanadis C: Fish consumption among healthy adults is associated with decreased levels of inflammatory markers related to cardiovascular disease: the ATTICA study. J Am Coll Cardiol 2005;46:120-124.

27 Patterson E, Wall R, Fitzgerald GF, Ross RP, Stanton C: Health implications of high dietary omega-6 polyunsaturated Fatty acids. J Nutr Metab 2012;2012:539426.

-28 Flock MR, Kris-Etherton PM: Diverse physiological effects of long-chain saturated fatty acids: implications for cardiovascular disease. Curr Opin Clin Nutr Metab Care 2013;16:133-140.

29 Micha R, Mozaffarian D: Saturated fat and cardiometabolic risk factors, coronary heart disease, stroke, and diabetes: a fresh look at the evidence. Lipids 2010;45:893-905.

-30 Hwang D: Modulation of the expression of cyclooxygenase- 2 by fatty acids mediated through toll-like receptor 4-derived signaling pathways. FASEB J 2001;15:2556-2564. 